\title{
Boron Carbide Amorphous Solid with Tunable Band Gap
}

\author{
Mikel Tucker ${ }^{\mathrm{a}}$, Sz-Chian Liou ${ }^{\mathrm{b}}$, Mobolaji Zondode ${ }^{\mathrm{a}}$, Jesse Dampare ${ }^{\mathrm{a}}$, Halim \\ C. Joseph ${ }^{\mathrm{a}, \mathrm{c}}$, Marieme Soda Ndaw ${ }^{\mathrm{a}}$, Jie Hou ${ }^{\mathrm{a}}$, Saroj Pramanik ${ }^{\mathrm{d}}$, Xiaobo Du ${ }^{\mathrm{g}}$, \\ Wei $\mathrm{Wu}^{\mathrm{h}}$, Jessye Leigh Bemley Talley ${ }^{\mathrm{c}}$, Abdellah Lisfi $^{\mathrm{a}}$, Maohong Fani ${ }^{\mathrm{f}}$, \\ Yong-Le Pan ${ }^{\mathrm{e}}$, Yucheng Lan ${ }^{\mathrm{a}}$ \\ ${ }^{a}$ Department of Physics and Engineering Physics, Morgan State University, Baltimore, \\ Maryland 21251 \\ ${ }^{b}$ Advanced Imaging and Microscope Laboratory, Maryland NanoCenter, University of \\ Maryland, MD 20742 \\ ${ }^{c}$ Department of Industrial and Systems Engineering, Morgan State University, Baltimore, \\ MD 21251 \\ ${ }^{d}$ Department of Biology, Morgan State University, Baltimore, Maryland 21251 \\ ${ }^{e} C C D C$ - Army Research Laboratory, Adelphi, MD 20783 \\ ${ }^{f}$ Department of Chemical and Petroleum Engineering, University of Wyoming, Laramie, \\ WY 82071 \\ ${ }^{g}$ Department of Physics, Jilin University, Changchun, China \\ ${ }^{h}$ London Centre for Nanotechnology, University College London, Gower Street, London \\ WC1E $6 B T, U K$
}

\begin{abstract}
Boron carbide $\mathrm{B}_{x} \mathrm{C}(x=1 / 6-10)$ powders were synthesized through a microwave-assisted carbothermic reduction reaction as a potential clean energy material. Their crystallographic structures and optical properties were characterized. X-ray diffraction and electron diffraction indicated that the synthesized $\mathrm{B}_{x} \mathrm{C}$ powders were amorphous. Electron energy-loss spectroscopy demonstrated that the composition of boron and carbon was in amorphous materials, and their chemical bonding were disclosed from Raman scattering spectroscopy. UV-vis absorption spectroscopy indicated that the bandgap of the bulks varied from $2.30 \mathrm{eV}$ to $3.90 \mathrm{eV}$, tuned by the boron/carbon element ratio. The synthesized powders were potential photovoltaic materials. A short-range ordering model was established to explain the optical properties.
\end{abstract}

Keywords: boride, optical, carbothermic reaction, photovoltaic

*Corresponding author. Tel: 01 443-885-3752. E-mail: yucheng.lan@morgan.edu. 


\section{Introduction}

Boron carbide with chemical formula $\mathrm{B}_{x} \mathrm{C}$ is an important member of the boride family. Many boride compounds possess unique properties and attract wide attention in science and industry. For example, cubic boron arsenide (BAs) 5 is a high thermal conductivity material whose thermal conductivity is comparable to that of diamond and graphite 1, 2, 3, 4. Magnesium diboride $\left(\mathrm{MgB}_{2}\right)$ is a multi-band superconductor whose superconducting mechanism can be primarily described by BCS theory [5]. Boron nitride $(\mathrm{BN})$ is the hardest material after diamond or even rivals diamond [6, 7. Boron carbide is the most popular commercialized boride. $\mathrm{B}_{x} \mathrm{C}$ shows super-high hardness, good electric conductivity, and low mass-density, being widely utilized in industry [8, 9, 10. The material is also a high-temperature thermoelectric material working around $1000{ }^{\circ} \mathrm{C}$ [11, 12. Recent research indicated that nanocrystalline structuring could noticeably improve the mechanical properties of $\mathrm{B}_{x} \mathrm{C}$ ceramic [13] and is also an effective approach to enhance thermoelectric properties [14, 15. Therefore, it is interesting to investigate nanostructuring or even amorphous $\mathrm{B}_{x} \mathrm{C}$. Excellent mechanical / thermoelectric performances would be expected from nanostructured $\mathrm{B}_{x} \mathrm{C}$ bulks that were fabricated from nano- / amorphous $\mathrm{B}_{x} \mathrm{C}$ starting materials. Here, the unique optical properties of $\mathrm{B}_{x} \mathrm{C}$ was reported in an amorphous state.

$\mathrm{B}_{x} \mathrm{C}$ has been synthesized with various methods. $\mathrm{B}_{4} \mathrm{C}$ single crystals were synthesized by the self-propagating technique at high-temperatures [16, 17, as well as $\mathrm{B}_{x} \mathrm{C}(x=4-12)$ [18. $\mathrm{B}_{4} \mathrm{C}$ nanocrystalline powders [19, 20, and nanofibers/nanobelts were synthesized using carbothermic reaction [21]. Boron-

rich $\mathrm{B}_{13} \mathrm{C}_{2}$ nanowires were produced by a simple annealing process from $\mathrm{B}_{4} \mathrm{C}$ powders [22]. $\mathrm{B}_{4} \mathrm{C}$ nanoparticles could be formed by thermal decomposition [23] and the sol-gel method [24]. The compound was also synthesized by magnesiothermic reductions, vapor-phase reactions, liquid-phase reactions, and other methods [9]. Among these methods is the microwave-assisted carbothermal 
reduction, which is fast and cost-effective in synthesizing $\mathrm{B}_{x} \mathrm{C}$ nanomaterials, such as $\mathrm{B}_{4} \mathrm{C}$ boron carbide nanocrystalline powders [19, 25] and carbon-rich $\mathrm{BC}_{2}$ amorphous powders [26. The carbothermal reduction technique has also been employed to synthesize metal nitrides [27], TiC powders [28, $\mathrm{ZrB}_{2}$ powders [29], and $\mathrm{TiB}_{2}$ powders [30]. Here, semiconducting boron carbon amorphous 35 compounds with tunable bandgap were first synthesized using the microwaveassisted carbothermal reaction. Corresponding structures and optical properties of the synthesized materials were investigated.

\section{Experimental}

The $\mathrm{B}_{x} \mathrm{C}$ materials were synthesized by a sol-gel and microwave-assistant carbothermic reaction. Precursors were first prepared by a sol-gel process. Reagent pure sugar and boron acid were weighted according to an element ratio of boron and carbon $\mathrm{B}: \mathrm{C}=x: 1$, mechanically mixed, and dissolved in de-ionized water under continuous stirring at room temperature to form milky semi-transparent suspensions. The suspensions were then stirred at $100{ }^{\circ} \mathrm{C}$

45 to form colorless transparent solutions. The water in the solutions then evaporated gradually with time until yellowish or brownish transparent gels were produced after water were totally evaporated. The color of the produced gels changed from yellow to brown with the increasing of boron content. The transparent gels were then dehydrated in an oven at $110^{\circ} \mathrm{C}$ over three days to remove bound water residue. The dehydrated solids were collected as precursors of the carbothermic reaction. The precursors were then irradiated in graphite boats under $2.45 \mathrm{GHz}$ microwave irradiation for $60 \mathrm{~min}$. The products were cooled down naturally, and collected for examination at room temperature. The microwave power was set at $1.8 \mathrm{~kW}$ during the reaction. The finally produced solids were porous and black at high boron ratio $(x>0.5)$ and dark brown at low boron ratio $(x<0.5)$. The UV-vis absorption of the synthesized products increased with the synthesis time when the time was less than $30-45$ min. So a synthesis time of $60 \mathrm{~min}$ is chosen in the experiments 
The synthesized materials were characterized by X-ray powder diffraction green laser at $532 \mathrm{~nm}$ (Civillaser, LSR-PS-F).

The synthesized $\mathrm{B}_{x} \mathrm{C}$ powders were fabricated to dye-sensitized solar cells (DSSC). ITO glass with electrical conductivity of $20 \Omega / \mathrm{cm}$ was cut by diamond saw, cleaned in ultrasonicator, and dried in air as electrodes. $\mathrm{B}_{x} \mathrm{C}$ was thickness of the $\mathrm{B}_{x} \mathrm{C}$ film was $20 \mu \mathrm{m}$. The electrode was sensitized with blackberry dye at room temperature. Carbon black was deposited on another ITO glass as counter-electrode. The two electrodes were sealed together and an iodide/triiodide solution was injected between the electrodes as liquid electrolyte. 


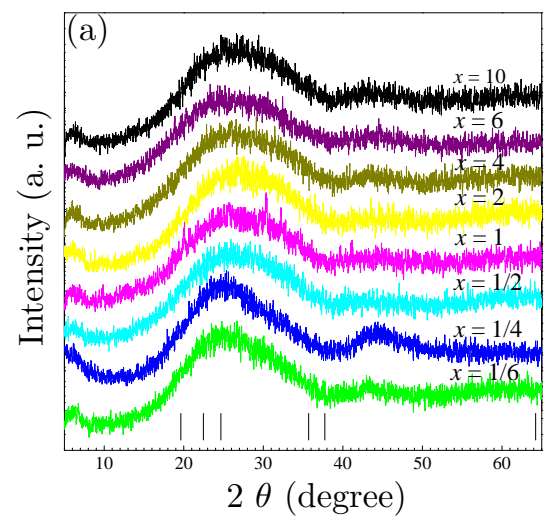

\section{(b)}

Figure 1: (a) X-ray diffraction patterns of synthesized powders with various initial element ratio of $B_{x} C(x=1 / 6-10)$. The peak positions of $B_{4} C$ (PDF \# 75-0424) were also indicated for comparison. (b) An SAED pattern of one $B_{2} C$ sample.

90 The fabricated DSSC was then connected to a potentiometer and illuminated under a tungsten-halogen light source with power of $1,000 \mathrm{~W}$. The output current and voltage were measured respectively by a Keithley Autoranging Microvolt DMM with a resolution of $10 \mathrm{nA}$ and a Fluke 8840A Programmable Multimeter with a resolution of $1 \mu \mathrm{V}$.

\section{Results and Discussion}

Figure 1 17 shows the X-ray diffraction patterns of the synthesized powders with difference carbon/boron ratio. Similar X-ray diffraction peaks are observed 


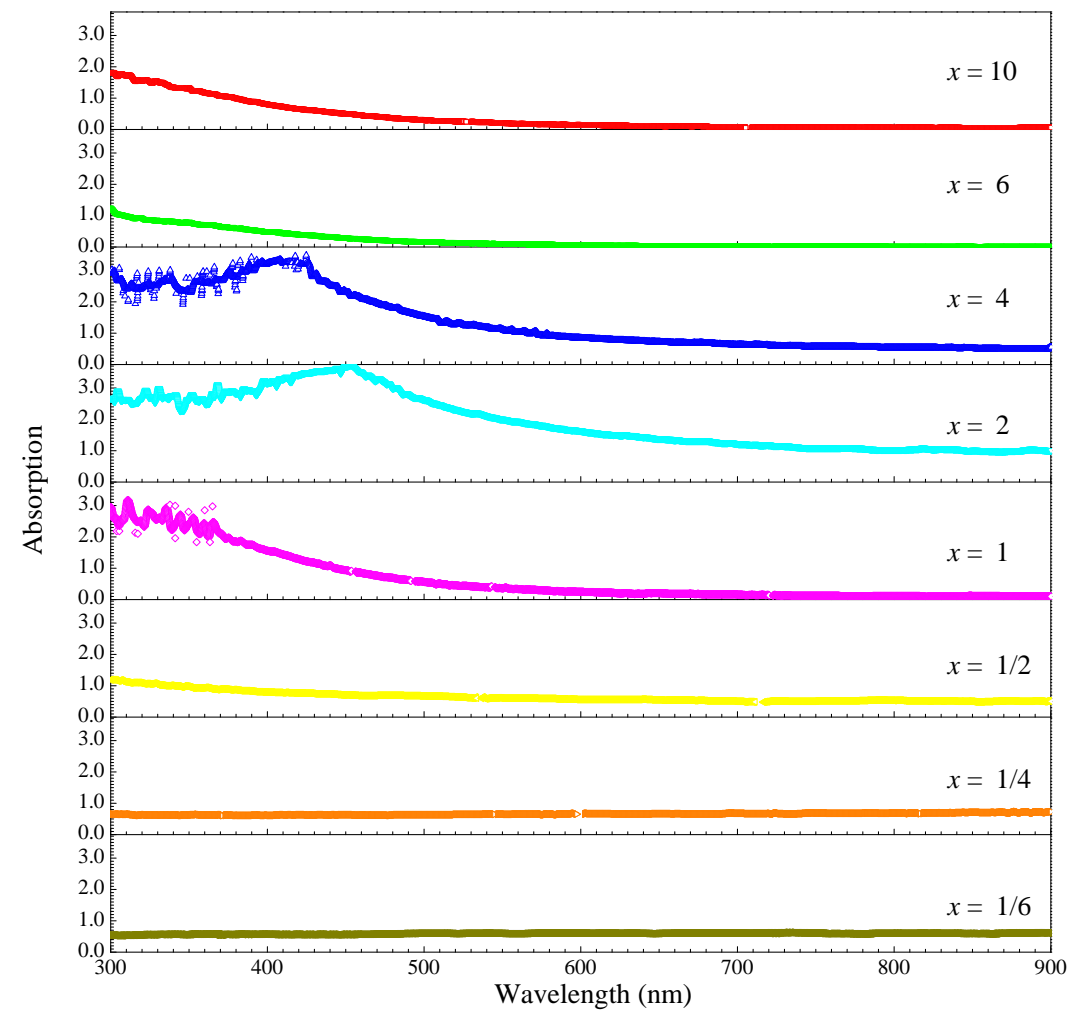

Figure 2: $U V$-vis spectra of $B_{x} C$ powders $(x=1 / 6-10)$.

in all synthesized powders with the initial $\mathrm{B} / \mathrm{C}$ ratio $x$ from $x=1 / 6$ to $x=10$. There are broadening peaks around $25^{\circ}$, with the barely noticeable sharp peaks around $6^{\circ}$ and $44^{\circ}$, indicating that the synthesized materials are mainly in amorphous form. The broadening peaks do not match these peaks of $\mathrm{B}_{4} \mathrm{C}(\mathrm{PDF}$ \# 75-0424) neither $\mathrm{B}_{13} \mathrm{C}_{2}$ (PDF \# 71-0585). No peaks of $\mathrm{B}_{4} \mathrm{C}$ (such as (021) at $2 \theta=37.8^{\circ},(104)$ at $2 \theta=35.0^{\circ}$, and (012) $2 \theta=23.5^{\circ}$ 32] ) are observed. No peaks of crystalline carbon, boron, or boron oxide are observed either.

TEM SAED patterns only reveals the diffuse rings, confirming the amorphous phase of the $\mathrm{B}_{x} \mathrm{C}$ samples in this study. Figure $1 \mathrm{~b}$ shows such a kind of diffuse pattern of $\mathrm{B}_{2} \mathrm{C}$ samples. The electron diffraction result is in agreement with the result from the X-ray diffraction. 
Figure 2 shows the UV-vis absorption spectra of $\mathrm{B}_{x} \mathrm{C}(x=1 / 6-10)$ with various $\mathrm{B}$ content. The $\mathrm{UV}$-vis absorption of $\mathrm{B}_{x} \mathrm{C}(x=1 / 6,1 / 4)$ is very low and there is little absorption when boron is at low concentration $(x<0.25)$. Observable absorptions are only detected in high-boron $\mathrm{B}_{x} \mathrm{C}(x \geq 0.5)$ samples. The absorption spectra further indicate that the synthesized $\mathrm{B}_{x} \mathrm{C}$ powders (with an initial element ratio $x=0.5-10$ ) can significantly absorb UV-vis light from $240 \mathrm{~nm}$ to $500 \mathrm{~nm}$, depending on boron/carbon ratio $x$. Therefore the boronrich $\mathrm{B}_{x} \mathrm{C}(x=1 / 2-10)$ samples should be one kind of semiconductors with wide bandgaps. Their absorption edges varied with carbon content.

In order to study the band-structures of the semiconducting samples, the bandgaps of $\mathrm{B}_{x} \mathrm{C}(x=1-10)$ samples are calculated from the Tauc method [31, following

$$
\alpha h \nu=A\left(h \nu-E_{g}\right)^{n}
$$

where $h$ is the Planck's constant, $\nu$ is the photon's frequency, $\alpha$ is the absorption coefficient, $E_{g}$ is the bandgap, $n$ is a proportionality constant, and $A$ is a constant. The value of the exponent $n$ denotes the characterictis of the electronic transition. Here only band-gaps of boron-rich $\mathrm{B}_{x} \mathrm{C}(x>0.5)$ samples are calculated from the UV-vis spectra shown in Figure 2 because of little absorption of these carbon-rich samples with $x<0.5$.

The relationships of $(\alpha h \nu)^{1 / n}$ and $h \nu$ of these UV-vis spectra were examined by the trial and error approach for $n=2,1 / 2,3,3 / 2$, corresponding to allowed indirect and direct, forbidden indirect and direct band-gap, respectively. We found that a better linear relationship existed when $n=1 / 2$. Therefore the synthesized amorphous $\mathrm{B}_{x} \mathrm{C}$ powders should possess direct bandgaps. Figure $3 \mathrm{a}$ shows the Tauc plots of the $\mathrm{B}_{x} \mathrm{C}(x=1-10)$ powders when $n=1 / 2$.

The bandgap $E_{g}$ of each sample can be obtained by extrapolating the linear portion of its Tauc plot to $(\alpha h \nu)^{2}=0$. The bandgap of the $\mathrm{B}_{x} \mathrm{C}$ powders determined from the Tauc plot is plotted as Figure $3 \mathrm{~b}$. The $\mathrm{B}_{2} \mathrm{C}$ powders have the narrowest direct bandgap of $2.25 \mathrm{eV}$, smaller than others (such as $2.6 \mathrm{eV}$ 

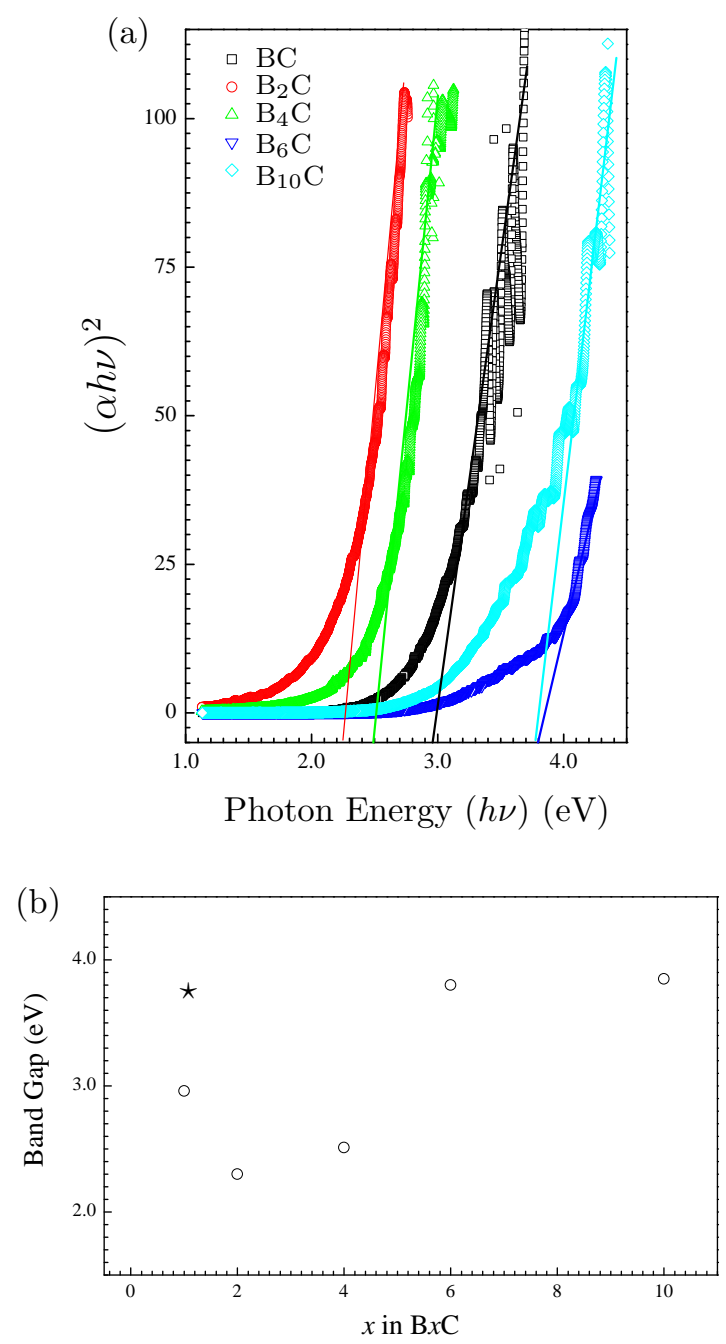

Figure 3: (a) Tauc plots and (b) Band-gaps of $B_{x} C$ powders $(x=1-10) . \star$ : reported amorphous BC films [33]. 


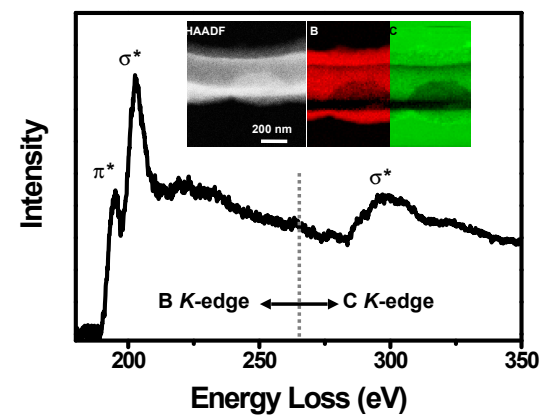

Figure 4: Core-loss EELS spectrum of $B_{2} C$ powder, showing boron and carbon K-edges.

for $\mathrm{B}_{4} \mathrm{C}$ and $2.95 \mathrm{eV}$ for $\mathrm{BC}$ samples). This is in good agreement with the absorption spectra shown in Figure 2.

The measured bandgaps of $\mathrm{B}_{x} \mathrm{C}(x=1-10)$ are $2.25 \mathrm{eV}-3.80 \mathrm{eV}$, wider than that of reported $\mathrm{B}_{4} \mathrm{C}$ compounds $(2.09 \mathrm{eV}$ [34] or $0.15 \mathrm{eV}[35])$ and homogenous $\mathrm{B}_{x} \mathrm{C}(x=4.3-11)(1.560-1.5695 \mathrm{eV}[34)$. The bandgaps are also higher than that of reported hydrogenated amorphous boron $(0.90-2.19 \mathrm{eV}$ [36]) and crystal boron $(1.5-2.1 \mathrm{eV}$ [37]) but closed to that of amorphous diamond $(2.1-2.4 \mathrm{eV}[38])$ with high $s p^{3}$ proportion. The measured bandgap is close to theoretical band-gap of crystalline $\mathrm{B}_{4} \mathrm{C}(2.6-3.0 \mathrm{eV}[35)$ and some reported band gap of amorphous films (such as $\mathrm{B}_{0.52} \mathrm{C}_{0.48}$ films with a bandgap of about $3.8 \mathrm{eV}$ [33]. The wide bandgaps should come from the unique microstructure of the synthesized samples, as discussed below.

In order to understand the optical properties of the $\mathrm{B}_{x} \mathrm{C}$ samples, we investigated the microstructure and chemical bonds of the synthesized borides by EELS on TEM and Raman scattering respectively. The $\mathrm{B}_{2} \mathrm{C}$ powder was chosen among these $\mathrm{B}_{x} \mathrm{C}$ samples for further characterizations because of its narrowest bandgap shown in Figure 3b and the strongest / widest absorption shown in Figure 2.

EELS is a powerful tool to detect light elements besides traditional X-ray photoelectron spectroscopy, second ion mass spectrometry, inductively coupled plasma spectroscopy, and electron probe microanalysis. Here EELS is employed 
to detect composited elements of the samples at nanoscale. Figure 4 shows a typical EELS spectrum of one $\mathrm{B}_{2} \mathrm{C}$ sample (inset is STEM HAADF image). The EELS spectrum indicates that the material contains the boron and carbon, and no oxygen is detected. The electron energy loss near edge structure (ELNES) of boron (B) K-edge reveals two sharp edges at the energy of $\sim 194 \mathrm{eV}$, and $\sim 202.8 \mathrm{eV}$ which can be assigned as $\pi^{*}\left(s p^{2}\right.$ bonding $)$ and $\sigma^{*}$ ( $s p^{3}$ bonding $)$ peaks, respectively, and one broad feature at the energy of $\sim 217 \mathrm{eV}$. Those spectral features are similar to these of BN nanomaterials [39, 40, 41], amorphous boron [42, 43], and crystalline $\mathrm{B}_{4} \mathrm{C}$ nano-inclusions [4]. Additionally the $\sigma^{*}$ peak in $\mathrm{B}_{2} \mathrm{C}$ reveals sharp peaks unlike the broad features in other $\mathrm{B}_{4} \mathrm{C}$ materials in different crystallinity and morphology 45, 46, 47, 48. The existence of $\pi^{*}$ peak strongly supports the chemical bonding between $\mathrm{B}$ and $\mathrm{C}$ atoms. 170 The ELNES of carbon K-edge only exhibits the broad $\sigma^{*}$ peak which is similar to C K-edge features in diamond with $s p^{3}$ hybridization unlike the graphite contained the additional $\pi^{*}$ peak. It indicates significant $s p^{3}$ hybridizations in the synthesized amorphous $\mathrm{B}_{2} \mathrm{C}$ compounds

In order to characterize the $\mathrm{B}$ distribution within the materials, HAADF imaging and EELS spectrum imaging were carried out on the as-synthesized nanomaterials [26]. Both HAADF images and EELS elemental mapping of boron and carbon (inserts in Figure 4 ) indicate that boron and carbon uniformly distributed at the nanoscale. No boron-rich or carbon-rich regions were observed in this study. In addition, neither oxygen nor nitrogen is noticeably observed from EDS and EELS spectra in this study. Therefore, it is reasonable to conclude that the synthesized nanomaterials are one kind of uniform B-C materials.

The chemical bonding of the $\mathrm{B}_{x} \mathrm{C}$ powders was examined by the Raman scattering spectra. Figure 5 shows a typical Raman scattering spectrum of the 185 synthesized $\mathrm{B}_{2} \mathrm{C}$ sample. In comparison with the Raman spectra from crystalline $\mathrm{B}_{4} \mathrm{C}$ [49], amorphous $\mathrm{B}_{4} \mathrm{C}$ [50, $\mathrm{B}_{11} \mathrm{C}$ [51], crystalline $\alpha$-rhombohedral boron [49, and amorphous boron, the Raman bands here ranging from $550 \mathrm{~cm}^{-1}$ to $1200 \mathrm{~cm}^{-1}$ can be assigned to the B-B bond (chain rotating and breathing 


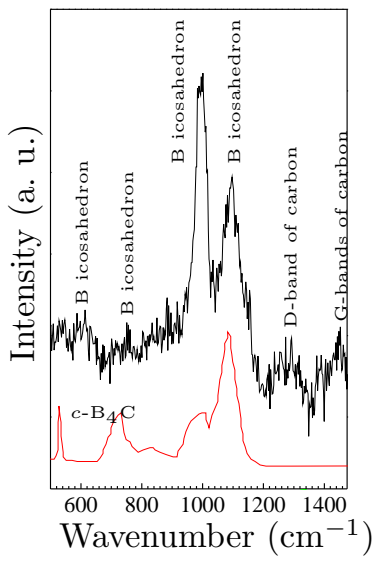

Figure 5: Raman scattering spectrum of the $B_{2} C$ sample. A Raman spectrum of singlecrystalline $B_{4} C$ [49] (c- $\left.B_{4} C\right)$ is plotted for comparison.

modes of icosahedral $\mathrm{B}_{11} \mathrm{C}$ or $\left.\mathrm{B}_{12}\right)$. It was reported that the Raman bands in the $600-1200 \mathrm{~cm}^{-1}$ range are associated with the icosahedral modes and relatively unaffected by the carbon content of icosahedrons [49] while strongly affected by the structure of the B-cage icosahedral and disordering boron. So the two B-C bonds near $1,100 \mathrm{~cm}^{-1}$ were reserved in the amorphous samples, as observed in reported amorphous boron carbides [52]. Here individual $\mathrm{B}_{11} \mathrm{C}$ or $\mathrm{B}_{12}$ icosahedrons should be formed, possess strong chemical bonding around boron atoms. However, the bands of the icosahedrons are too weak from $550 \mathrm{~cm}^{-1}$ to $800 \mathrm{~cm}^{-1}$ and hard to be distinguished from background. The bands in $1200-1500 \mathrm{~cm}^{-1}$ can be assigned to the D-band and G-band of amorphous carbon. It was reported that disordering carbon atoms would result in Raman peak broadening and shifts of the carbon bands [53. The broad and weak Dband and G-band here maybe come from high disordering of carbon atoms in the synthesized powders, or the effect of B-icosahedrons.

Based on the above Raman analyses, it is reasonable to assume that isolating B-icosahedrons $\left(\mathrm{B}_{11} \mathrm{C}\right.$ or $\left.\mathrm{B}_{12}\right)$ are formed in the synthesized powders. Carbon 205 atoms should randomly occupy spaces between the boron-icosahedrons, weakly bonding with boron atoms. 
A structural model of the synthesis samples can then be established from the experimental analyses of the Raman and EELS characterizations. The amorphous powders should consist of short-range ordering boron icosahedrons $\left(\mathrm{B}_{11} \mathrm{C}\right.$ or $\mathrm{B}_{12}$ ) and amorphous carbon. Carbon atoms distribute randomly among the boron icosahedrons, working as fillers and bonding to the icosahedrons. The crystalline boron icosahedrons would provide semiconducting characters while amorphous carbon fillers tune the bandgaps of the synthesized samples.

The short-range ordering model is closed to other reported theoretical structure. Ivashchenko and Shevchenko proposed a structure of amorphous $\mathrm{B}_{4} \mathrm{C}$, a random icosahedral network connected with the amorphous B-C matrix, to carry out density function theory calculation [54. Pallier et al. reported a similar microstructure in amorphous boron carbide $\mathrm{B}_{2.5} \mathrm{C}$ ceramic [55]. It was assumed that the amorphous boron carbide was essentially made of random icosahedrons $\left(\mathrm{B}_{12}, \mathrm{~B}_{11} \mathrm{C}, \mathrm{B}_{10} \mathrm{C}_{2}\right)$ embedded in amorphous $\mathrm{BC}_{3} / \mathrm{BC}_{2} \mathrm{~B}$ and $\mathrm{CB}_{4}$ matrix. Such kind of icosahedron-based random network was also reported in amorphous $\mathrm{B}_{1-x} \mathrm{C}_{x}$ films [52. Paquette et al. experimentally investigated local physical structure of amorphous hydrogenated $\mathrm{B}_{3} \mathrm{C}$ films using magic angle spinning solid-state NMR spectroscopy [56. NMR data indicated that carbon existed as extra-icosahedons rather than in segregated phases. Therefore, it is most possible that the amorphous $\mathrm{B}_{x} \mathrm{C}$ here are also composed of disordered boronicosahedra that are connected by an amorphous carbon matrix. The content of carbon could be continuously adjustable to fill the spaces among the boronicosahedrons, showing no limit solid solubility in the synthesized powders. The total chemical bonding between carbon and boron-icosahedrons would change with the $\mathrm{B} / \mathrm{C}$ ratio, resulting in continuous change of its optical properties. On the contrary, it is difficult to tune bandgap of crystalline $\mathrm{B}_{x} \mathrm{C}$ compounds because of limited solubility of carbon in borides.

Annen et al. qualitatively and quantitatively analyzed the bonding structure of amorphous hydrogenated boron-carbon thin films using Fourier transform infrared spectroscopy [57. It was found that carbon was predominantly $s p^{3}$ hybridized and bonded between boron neighbors in low-carbon-content $\mathrm{B}_{x} \mathrm{C}$ 
$(x<2.3)$ samples while the $s p^{2}$ hybridized carbon increased with carbon content. The increasing carbon-carbon bonds dominated the cross-link network in high-carbon-content $\mathrm{B}_{x} \mathrm{C}(x>2.3)$ samples. This maybe the same reason why the optical properties of our $\mathrm{B}_{x} \mathrm{C}$ samples can be continuously tuned with $\mathrm{B} / \mathrm{C}$ ratio.

The structural model can explain the high carbon content in $\mathrm{B}_{x} \mathrm{C}$ samples. According to the boron-carbon phase diagram [58, the boron carbide phase exists in the homogeneity range when the carbon content is $9-20$ at \%. So the $\mathrm{B}$-rich $\mathrm{B}_{x} \mathrm{C}$ powders (such as $\mathrm{B}_{10} \mathrm{C}$ and $\mathrm{B}_{6} \mathrm{C}$ here) should be single-phase boron carbide. Here, carbon-rich $\mathrm{B}_{1 / 2} \mathrm{C}, \mathrm{BC}$, and $\mathrm{B}_{2} \mathrm{C}$ were also successfully synthesized, in which the carbon content is higher than 33 at \%. According to the phase diagram, graphite and boron carbide should co-exist once the carbon content is higher than 20 at \%, not one single-phase boron carbide. A most possible explanation is that extra carbon atoms are bonded to boron-icosahedra clusters, being amorphous state, not form the crystalline phase to follow the phase diagram.

The model is also in agreement with chemical activities of the synthesized samples. X-ray powder diffraction indicated that the synthesized powders were stable in air for weeks while the amorphous powders transformed into boron trioxide and amorphous carbon in water. It was reported that crystalline boron does not react with air and water under normal conditions [59]. However, atomic boron atoms and isolating boron icosahedra should be more active and reactive with oxygen and water at room temperature. Differential scanning calorimetry (DSC) indicated the powders are stable up to $600{ }^{\circ} \mathrm{C}$ in protective atmosphere (Figure S1).

The structural model is also indirectly supported by a calculated optical absorption of amorphous $\mathrm{B}_{2} \mathrm{C}$ solid. If $\mathrm{B}_{2} \mathrm{C}$ is fully amorphous without any crystalline boron-icosahedrons, a maximum excitation was expected at $7.7 \mathrm{eV}$, as shown in Figure S2, far away from the measured bandgap of the $\mathrm{B}_{2}$ samples. Thus, the synthesized samples should not be amorphous at the atomic level and a short-range order should exist in the amorphous samples. 


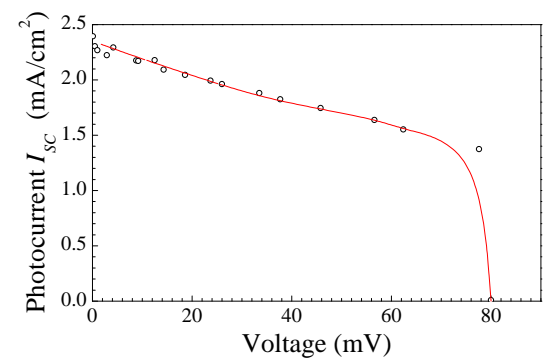

Figure 6: Measured current-voltage characteristics of a BC-based DSSC under AM 1.5 solar irradiation.

The amorphous $\mathrm{B}_{2} \mathrm{C}$ samples can absorb ultraviolet-visible light from $300 \mathrm{~nm}$ to $600 \mathrm{~nm}$. So the $\mathrm{B}_{2} \mathrm{C}$ sample should have potential applications in photovoltaic cells. Figure 6 shows a current-voltage (I-V) curve of a $\mathrm{B}_{2} \mathrm{C}$-based DSSC device. The short-circuit current density of the device $J_{s c}=2.3 \mathrm{~mA} / \mathrm{cm}^{2}$, opencircuit voltage $V_{o c}=85 \mathrm{mV}$, and fill factor $F F \sim 70 \%$. The short-circuit current density and open-circuit voltage are lower than those of $\mathrm{TiO}_{2}$-based $\operatorname{DSSC}\left(J_{s c}=10-20 \mathrm{~mA} / \mathrm{cm}^{2}, V_{o c}=600-900 \mathrm{mV}\right.$ 60, 61] $)$. However, the fill facto is close to that $\mathrm{TiO}_{2}$-based $\operatorname{DSSC}(F F \sim 70 \%$ 60, 61] $)$. The excellent fill factor should be contributed to the wide UV-vis absorption of the amorphous material. More work is being carried out to improve the carbide-based DSSC behaviors through more efficient counter-electrodes and dyes.

\section{Conclusion}

Semiconducting boron-carbon $\left(\mathrm{B}_{x} \mathrm{C}\right)$ compound was synthesized by a microwave-assisted carbothermic reaction from sol-gels. The synthesized $\mathrm{B}_{x} \mathrm{C}$ powders with a chemical formula of $\mathrm{B}_{x} \mathrm{C}(x=1 / 6-10)$ were amorphous with uniform distribution of boron and carbon at nanoscale. Their bandgaps are within $2.25-3.80 \mathrm{eV}$, depending on the boron/carbon ratio. The powders should consist of short-range ordering boron icosahedrons and amorphous carbon. Such semiconducting amorphous materials have potential applications in photovoltaics. 


\section{Acknowledgments}

290

YL is partially supported by the Department of Energy under Award Number DE-FE0031906.

\section{References}

[1] L. Lindsay, D. A. Broido, T. L. Reinecke, First-principles determination of ultrahigh thermal conductivity of boron arsenide: A competitor for diamond?, Physical Review Letters 111 (2) (2013) 025901. doi: 10.1103/PhysRevLett.111.025901

[2] J. S. Kang, M. Li, H. Wu, H. Nguyen, Y. Hu, Experimental observation of high thermal conductivity in boron arsenide, Science 361 (6402) (2018) 575 - 578. doi:10.1126/science.aat5522.

[3] S. Li, Q. Zheng, Y. Lv, X. Liu, X. Wang, P. Y. Huang, D. G. Cahill, B. Lv, High thermal conductivity in cubic boron arsenide crystals, Science 361 (6402) (2018) 579 - 581. doi:10.1126/science.aat8982

[4] F. Tian, B. Song, X. Chen, N. K. Ravichandran, Y. Lv, K. Chen, S. Sullivan, J. Kim, Y. Zhou, T.-H. Liu, M. Goni, Z. Ding, J. Sun, G. A. G. Udalamatta Gamage, H. Sun, H. Ziyaee, S. Huyan, L. Deng, J. Zhou, A. J. Schmidt, S. Chen, C.-W. Chu, P. Y. Huang, D. Broido, L. Shi, G. Chen, Z. Ren, Unusual high thermal conductivity in boron arsenide bulk crystals, Science 361 (6402) (2018) 582-585. doi:10.1126/science.aat7932.

310

[5] J. Nagamatsu, N. Nakagawa, T. Muranaka, Y. Zenitani, J. Akimitsu, Superconductivity at $39 \mathrm{~K}$ in magnesium diboride, Nature 410 (6824) (2001) 63 - 64. doi:10.1038/35065039.

[6] N. Dubrovinskaia, V. L. Solozhenko, N. Miyajima, V. Dmitriev, O. O. Kurakevych, L. Dubrovinsky, Superhard nanocomposite of dense polymorphs 
of boron nitride: Noncarbon material has reached diamond hardness, Applied Physics Letters 90 (10) (2007) 101912. doi:10.1063/1.2711277.

[7] Z. Pan, H. Sun, Y. Zhang, C. Chen, Harder than diamond: Superior indentation strength of wurtzite BN and lonsdaleite, Physical Review Letters 102 (5) (2009) 055503. doi:10.1103/PhysRevLett.102.055503.

[8] F. Thévenot, Boron carbide - a comprehensive review, Journal of the European Ceramic Society 6 (4) (1990) 205-225. doi:10.1016/0955-2219(90) $90048-\mathrm{K}$

[9] A. K. Suri, C. Subramanian, J. K. Sonber, T. S. R. C. Murthy, Synthesis and consolidation of boron carbide: a review, International Materials 325 Reviews 55 (1) (2010) 4 - 40. doi:10.1179/095066009X12506721665211.

[10] V. Domnich, S. Reynaud, R. A. Haber, M. Chhowalla, Boron carbide: Structure, properties, and stability under stress, Journal of the American

ㅁ Ceramic Society 94 (11) (2011) 3605 - 3628. doi:10.1111/j.1551-2916. 2011.04865.x.

330 [11] C. Wood, Materials for thermoelectric energy conversion, Reports on Progress in Physics 51 (4) (1988) 459. doi:10.1088/0034-4885/51/4/001

[12] M. Tucker, H. C. Joseph, J. Hou, H. Li, Y. Lan, A comprehensive review of boron carbide thermoelectirc materials, Molecules 25 (3) (2020) (submitted).

[13] K. Madhav Reddy, J. J. Guo, Y. Shinoda, T. Fujita, A. Hirata, J. P. Singh, J. W. McCauley, M. W. Chen, Enhanced mechanical properties of nanocrystalline boron carbide by nanoporosity and interface phases, Nature Communications 3 (2012) 1052. doi:10.1038/ncomms2047.

[14] B. Poudel, Q. Hao, Y. Ma, Y. Lan, A. Minnich, B. Yu, X. Yan, D. Wang, A. Muto, D. Vashaee, X. Chen, J. Liu, M. S. Dresselhaus, G. Chen, 
Z. Ren, High-thermoelectric performance of nanostructured bismuth antimony telluride bulk alloys, Science 320 (5876) (2008) 634 - 638. doi: $10.1126 /$ science.1156446.

[15] Y. Lan, A. J. Minnich, G. Chen, Z. Ren, Enhancement of thermoelectric figure-of-merit by a bulk nanostructuring approach, Advanced Functional Materials 20 (3) (2010) 357 - 376. doi:10.1002/adfm.200901512.

[16] S. V. Konovalikhin, V. I. Ponomarev, Carbon in boron carbide: The crystal structure of $\mathrm{B}_{11.4} \mathrm{C}_{3.6}$, Russian Journal of Inorganic Chemistry 54 (2) (2009) 197 - 203. doi:10.1134/S0036023609020053

[17] V. I. Ponomarev, I. D. Kovalev, S. V. Konovalikhin, V. I. Vershinnikov, Ordering of carbon atoms in boron carbide structure, Crystallography Reports 58 (3) (2013) 422 - 426. doi:10.1134/S1063774513030188

[18] T. L. Aselage, R. G. Tissot, Lattice constants of boron carbides, Journal of the American Ceramic Society 75 (8) (1992) 2207 - 2212. doi:10.1111/ j.1151-2916.1992.tb04485.x

[19] R. F. K. Gunnewiek, P. M. Souto, R. H. G. A. Kiminami, Synthesis of nanocrystalline boron carbide by direct microwave carbothermal reduction of boric acid, Journal of Nanomaterials 2017 (2017) 8. doi:10.1155/2017/ 3983468 .

[20] Y. Zhang, Y. Zhang, H. Gong, J. Yu, J. Zhao, Z. Zhang, Y. Zhang, Microwave-assisted sol-gel synthesis of neutron-absorbed nano-sized ${ }^{10} \mathrm{~B}-$ enriched $\mathrm{B}_{4} \mathrm{C}$ powders, Journal of Sol-Gel Science and Technology 80 (3) (2016) 683 - 689. doi:10.1007/s10971-016-4147-4.

[21] M. G. Rodríguez, O. V. Kharissova, U. Ortiz-Méndez, Formation of boron carbide nanofibers and nanobelts from heated by microwave, Reviews on Advanced Materials Science 7 (1) (2004) $55-60$. 
[22] H. Z. Zhang, R. M. Wang, L. P. You, J. Yu, H. Chen, D. P. Yu, Y. Chen, Boron carbide nanowires with uniform cnxcoatings, New Journal of Physics 9 (1) (2007) 13/1 - 13/9. doi:10.1088/1367-2630/9/1/013.

[27] B. Vaidhyanathan, K. J. Rao, Synthesis of Ti, Ga, and V nitrides: Microwave-assisted carbothermal reduction and nitridation, Chemistry of Materials 9 (5) (1997) 1196 - 1200. doi:10.1021/cm9605835

[28] H. Wang, W. Zhu, Y. Liu, L. Zeng, L. Sun, The microwave-assisted green

[29] Y. Zeng, F. Liang, J. Liu, J. Zhang, H. Zhang, S. Zhang, Highly efficient and low-temperature preparation of plate-like $\mathrm{ZrB}_{2}$-SiC powders by a molten-salt and microwave-modified boro/carbothermal reduction method, Materials 11 (10) (2018) 1811. doi:10.3390/ma11101811. 

preparation of $\mathrm{TiB}_{2}$ micro-platelets via boro/carbothermal reduction in microwave heated molten salt, Materials 12 (16) (2019) 2555. doi:10. $3390 / \mathrm{ma12162555.}$

[31] J. Tauc, R. Grigorovici, A. Vancu, Optical properties and electronic struc400 ture of amorphous germanium, Physica Status Solidi (b) 15 (2) (1966) 627 -637. doi:10.1002/pssb.19660150224.

[32] T. L. Aselage, R. G. Tissot, Lattice constants of boron carbides, Journal of the American Ceramic Society 75 (8) (1992) 2207 - 2212. doi:10.1111/ j.1151-2916.1992.tb04485.x.

[33] A. S. Anan'ev, O. I. Kon'kov, V. M. Lebedev, A. N. Novokhatski, E. I. Terukov, I. N. Trapeznikova, Fabrication and properties of amorphous hydrogenated boron carbide films, Semiconductors 36 (8) (2002) 941-943. doi:10.1134/1.1500477.

[34] H. Werheit, On excitons and other gap states in boron carbide, Journal of 410 Physics: Condensed Matter 18 (47) (2006) 10655 - 10662. doi:10.1088/ 0953-8984/18/47/011.

[35] T. A. Yıldız, M. Durandurdu, Amorphous boron carbide from $a b$ initio (1) simulations, Computational Materials Science 173 (2020) 109397. doi: 10.1016/j.commatsci.2019.109397.

[36] F. H. Cocks, P. L. Jones, L. J. Dimmey, The optical band gap of hydrogenated amorphousboron thin films: The effect of thermal treatment, Applied Physics Letters 36 (1980) 970. doi:10.1063/1.91386.

[37] J.-J. Chen, X.-J. Liang, B. Yang, J. Girard, V. Drozd, Z. Liu, Band gap of semiconducting high pressure phase of boron, in: 2016 International Conference on Material Science and Civil Engineering (MSCE 2016), 2017, pp. 172 - 180. doi:10.12783/dtmse/msce2016/10465 
[38] R. Lossy, D. L. Pappas, R. A. Roy, J. J. Cuomo, V. M. Sura, Filtered arc deposition of amorphous diamond, Applied Physics Letters 61 (2) (1992) 171 - 173. doi:10.1063/1.108208.

425 [39] J. Y. Huang, H. Yasuda, H. Mori, Hrtem and eels studies on the amorphization of hexagonal boron nitride induced by ball milling, Journal of

1 the American Ceramic Society 83 (2) (2000) 403 - 409. doi:10.1111/j. 1151-2916.2000.tb01204.x.

[40] J. E. Nocua, F. Piazza, B. R. Weiner, G. Morel, High-yield synthesis of stoichiometric boron nitride nanostructures, Journal of Nanomaterials 2009 (2009) 429360. doi:10.1155/2009/429360

[41] G. Zhu, S. Dong, J. Hu, Y. Kan, P. He, L. Gao, X. Zhang, H. Zhou, In situ growth behavior of boron nitride nanotubes on the surface of silicon carbide fibers as hierarchical reinforcements, RSC Advances 6 (2016) 14112 - 14119. doi:10.1039/C5RA23318F

[42] Y. Q. Wang, X. F. Duan, Crystalline boron nanowires, Applied Physics Letters 82 (2) (2003) 272 - 274. doi:10.1063/1.1536269.

[43] Y. Q. Wang, X. F. Duan, L. M. Cao, W. K. Wang, One-dimensional growth mechanism of amorphous boron nanowires, Chemical Physics Letters 359 (3) (2002) 273 - 277. doi:10.1016/S0009-2614(02)00732-7.

[44] Y.-G. Lu, S. Turner, E. A. Ekimov, J. Verbeeck, G. Van Tendeloo, Boronrich inclusions and boron distribution in HPHT polycrystalline superconducting diamond, Carbon 86 (2015) 156 - 162. doi:10.1016/j.carbon. 2015.01 .034

${ }_{445}$ [45] R. Ma, Y. Bando, High purity single crystalline boron carbide nanowires, 口 Chemical Physics Letters 364 (3) (2002) 314 - 317. doi:10.1016/ S0009-2614(02)01312-X.

[46] Kushita, Kouhei N., Hojou, Kiichi, Furuno, Shigemi, In situ EELS and TEM observation of boron carbide $\mathrm{B}_{4} \mathrm{C}$ during hydrogen- and helium-ion 
bombardments, Microscopy Microanalysis Microstructures 6 (1) (1995) 149

- 157. doi:10.1051/mmm:1995115

[47] M. W. Chen, J. W. McCauley, J. C. LaSalvia, K. J. Hemker, Microstructural characterization of commercial hot-pressed boron carbide ceramics, Journal of the American Ceramic Society 88 (7) (2005) 1935 - 1942. doi:10.1111/j.1551-2916.2005.00346.x

[48] Z. Wang, Y. Shimizu, T. Sasaki, K. Kawaguchi, K. Kimura, N. Koshizaki, Catalyst-free fabrication of single crystalline boron nanobelts by laser ablation, Chemical Physics Letters 368 (5) (2003) 663 - 667. doi:10.1016/ S0009-2614(02) 01964-4.

[49] D. R. Tallant, T. L. Aselage, A. N. Campbell, D. Emin, Boron carbide structure by raman spectroscopy, Physical Review B 40 (8) (1989) 5649 5656. doi:10.1103/PhysRevB.40.5649.

[50] X. Q. Yan, W. J. Li, T. Goto, M. W. Chen, Raman spectroscopy of pressure-induced amorphous boron carbide, Applied Physics Letters 88 (13) (2006) 131905. doi:10.1063/1.2189826.

[51] H. Werheit, U. Kuhlmann, Electron-phonon interaction in $\mathrm{B}_{12}$ icosahedra, Solid State Communications 88 (6) (1993) 421 - 425. doi:10.1016/ 0038-1098(93) 90605-M.

[52] K. Shirai, S. Emura, S. ichi Gonda, Y. Kumashiro, Infrared study of amorphous $\mathrm{B}_{1-x} \mathrm{C}_{x}$ films films, Journal of Applied Physics 78 (5) (1995) 3392 3400. doi:10.1063/1.359967.

[53] D. Beeman, J. Silverman, R. Lynds, M. R. Anderson, Modeling studies 口 of amorphous carbon, Physical Review B 30 (2) (1984) 870 - 875. doi: 10.1103/PhysRevB.30.870.

${ }_{475}$ [54] V. I. Ivashchenko, V. I. Shevchenko, P. E. A. Turchi, First-principles study of the atomic and electronic structures of crystalline and amorphous $\mathrm{B}_{4} \mathrm{C}$, 
Physical Review B 80 (23) (2009) 235208. doi:10.1103/PhysRevB.80. 235208,

[55] C. Pallier, J.-M. Leyssale, L. A. Truflandier, A. T. Bui, P. Weisbecker, C. Gervais, H. E. Fischer, F. Sirotti, F. Teyssandier, G. Chollon, Structure of an amorphous boron carbide film: An experimental and computational approach, Chemistry of Materials 25 (13) (2013) 2618-2629. doi:10.1021/ cm400847t.

[56] M. M. Paquette, W. Li, M. S. Driver, S. Karki, A. N. Caruso, N. A. Oyler, The local physical structure of amorphous hydrogenated boron carbide: insights from magic angle spinning solid-state NMR spectroscopy,

q Journal of Physics: Condensed Matter 23 (43) (2011) 435002. doi: 10.1088/0953-8984/23/43/435002.

[57] A. Annen, M. Sa $\beta$, R. Beckmann, A. von Keudell, W. Jacob, Structure of 490 plasma-deposited amorphous hydrogenated boron-carbon thin films, Thin

(4) Solid Films 312 (1) (1998) 147-155. doi:https://doi.org/10.1016/ S0040-6090(97)00735-9.

[58] M. Bouchacourt, F. Thevenot, The melting of boron carbide and the homogeneity range of the boron carbide phase, Journal of the Less Common Metals 67 (2) (1979) 327 - 331. doi:10.1016/0022-5088(79)90007-9.

[59] W. M. Haynes (Ed.), CRC Handbook of Chemistry and Physics, CRC Press, 2015.

[60] T. Miyasaka, Toward printable sensitized mesoscopic solar cells: Light- harvesting management with thin $\mathrm{TiO}_{2}$ films, Journal of Physical Chemistry Letters 2 (2011) 262 - 269. doi:10.1021/jz101424p

[61] M.-E. Yeoh, K.-Y. Chan, Recent advances in photo-anode for dye-sensitized solar cells: a review, International Journal of Energy Research 41 (15) (2017) 2446 - 2467. doi:10.1002/er.3764. 